\title{
CT angiography of the renal arteries and veins: normal anatomy and variants
}

\author{
Tuncay Hazırolan, Meryem Öz, Barış Türkbey, Ali Devrim Karaosmanoğlu, Berna Sayan Oğuz, \\ Murat Canyiğit
}

\begin{abstract}
Conventional angiography has long been regarded as gold standard imaging modality for evaluation of the renal vasculature. Introduction of multidetector computed tomography (MDCT) angiography had a groundbreaking impact on evaluation of the renal vessels and is gradually replacing conventional angiography as standard imaging. Herein, we review and illustrate the normal and variant anatomy of renal vessels with special emphasis on imaging protocols and reconstruction techniques in MDCT.
\end{abstract}

Key words: • computed tomography, X-ray • angiography - renal artery • renal vein
From the Department of Radiology (B.T. $\bowtie$ bturkbey@yahoo. com), Hacettepe University School of Medicine, Ankara, Turkey.

Received 17 June 2009; revision requested 20 July 2009; revision received 25 July 2009; accepted 30 July 2009.

Published online 9 February 2010 DOI 10.4261/1305-3825.DIR.2902-09.1
$\mathbf{M}$ ultidetector computed tomography angiography (MDCTA) plays an increasingly important role in the evaluation of the renal vasculature (1). Although conventional angiography is still regarded as the gold standard in renal vascular imaging, MDCTA is increasingly used as it is less invasive, easily applicable and available (2-4). MDCTA enables precise visualization of the normal and variant anatomy of several regions including the renal vasculature (5-7); however, the main drawbacks of MDCTA are the exposure to ionizing radiation and the use of potentially nephrotoxic iodinated contrast material. As such, its use is limited in children and pregnant women and in patients with impaired renal function.

Main clinical indications for renal MDCTA include the imaging workup for ruling out renovascular hypertension, renal transplant recipient and donor evaluation, acute onset flank pain in patients with coagulative disorders, direct renal trauma, arteriovenous communications, renal artery aneurysm, renal parenchymal or vascular calcifications, renal manifestations of a systemic disease (e.g., vasculitis, thromboembolic disease) (8).

\section{Technical considerations} Image acquisiton

Diagnostic accuracy of renal MDCTA depends on the quality of initial raw data acquired during the study. Adequate patient preparation, positioning, as well as the proper contrast material injection, are of paramount importance. CT protocol for the evaluation of the renal vasculature consists of both unenhanced and enhanced CT scans. Unenhanced scans of the kidneys and adrenal glands with contiguous sections of 3$\mathrm{mm}$ thickness are necessary for the evaluation of adrenal lesions, vascular calcifications, and renal calculi (Fig. 1).

The optimal anatomic coverage for the arterial phase scan, that is the principal part of the renal MDCT angiography, should include the region between the celiac artery and terminal part of the common iliac arteries (Fig. 2). However, in patients with ectopic or transplanted kidney, the coverage can be modified; for this purpose careful preprocedural evaluation of the patient including medical records should be done. Slices with a thickness of 1-1.5 mm are obtained after rapid injection of a $100-\mathrm{mL}$ bolus of $300-400 \mathrm{mg} / \mathrm{mL}$ non-ionic iodinated contrast at a rate of $4 \mathrm{~mL} / \mathrm{s}$ and a $70-\mathrm{mL}$ bolus at a rate of $5-6 \mathrm{~mL} / \mathrm{s}$ in 16 and 64-channel MDCT scanners, respectively. The scanning parameters are summarized in Table. Image acquisiton is initiated after a $4-5 \mathrm{~s}$ and $6-7 \mathrm{~s}$ delay in 16 and 64-channel MDCT scanners, respectively, when the threshold enhancement of $100 \mathrm{HU}$ is reached within the region of interest placed on the abdominal aorta. For the evaluation of renal venous structures and abdominal viscera whole abdomen is scanned with a section thickness 


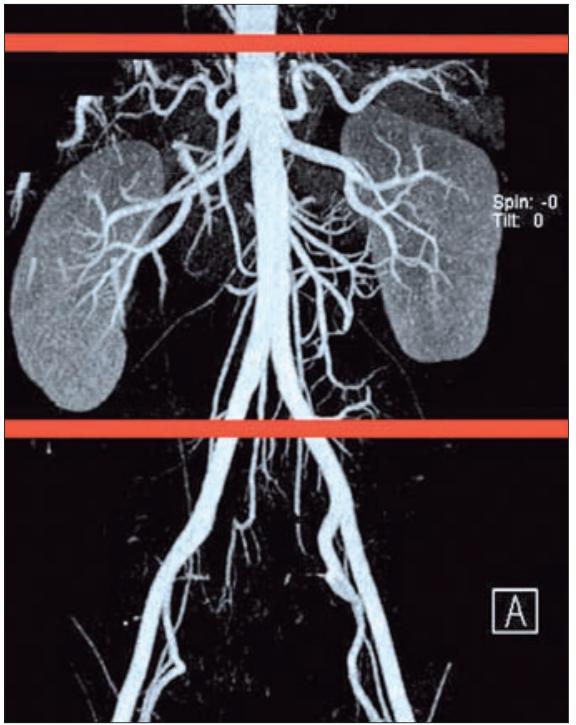

Figure 1. Non-contrast scanning area includes the adrenal glands and kidneys. These images provide important information about the focal lesions of the adrenal gland, renal stones, and vessel wall calcifications.

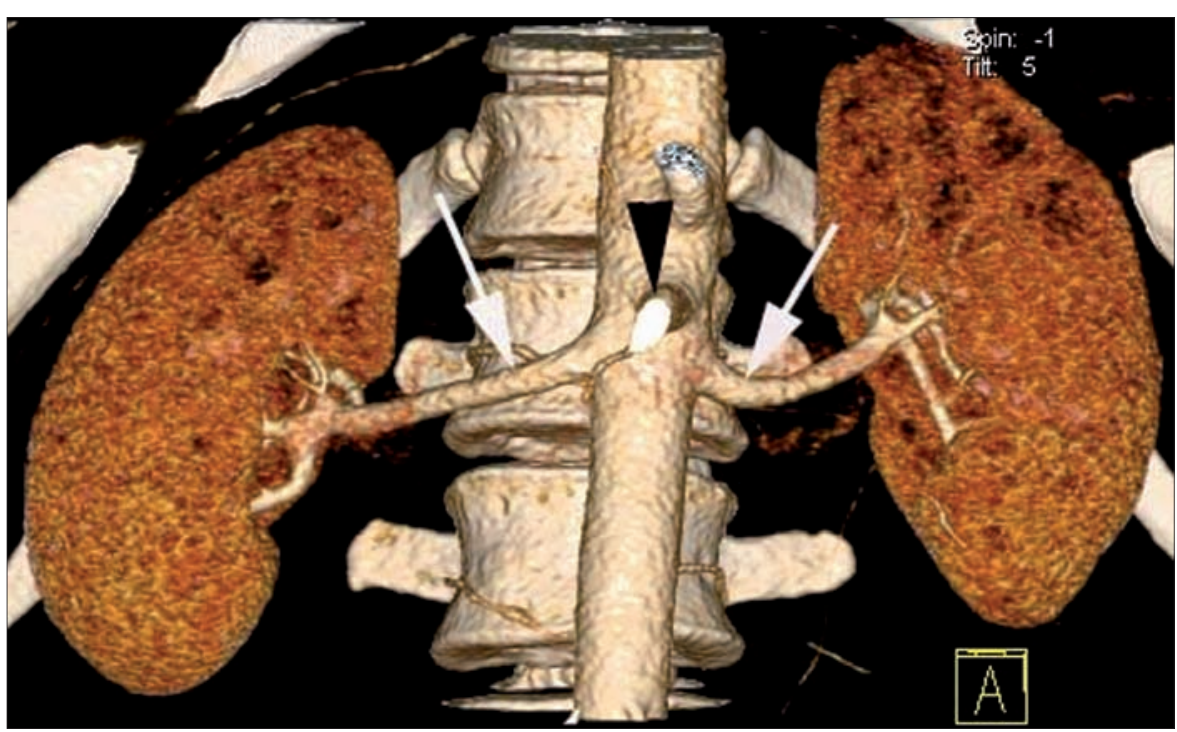

Figure 3. Volume rendering image demonstrates the normal anatomy of the renal arteries (arrows). The renal arteries typically arise from the aorta at the level of L1-L2 intervertebral disk space below the origin of the SMA (arrowhead).

Table. MDCT scanning parameters used in renal CT angiography

\begin{tabular}{|c|c|c|c|c|c|c|}
\hline & \multicolumn{3}{|c|}{$16 \mathrm{MDCT}$} & \multicolumn{3}{|c|}{$64 \mathrm{MDCT}$} \\
\hline & Unenhanced & Arterial & Venous & Unenhanced & Arterial & Venous \\
\hline $\mathrm{KV} /$ effective mAs & $120 / 140$ & $140 / 140$ & $120 / 140$ & $120 / 160$ & $120 / 150$ & $120 / 160$ \\
\hline Rotation time (s) & 0.5 & 0.5 & 0.5 & 0.5 & 0.33 & 0.5 \\
\hline Detector collimation ( $\mathrm{mm}$ ) & 1.5 & 0.75 & 1.5 & 1.2 & 0.6 & 1.2 \\
\hline Slice thickness $(\mathrm{mm})$ & 3 & 1 & 5 & 3 & 1 & 5 \\
\hline Pitch & 1.25 & 1.5 & 1.25 & 1.4 & 1.4 & 1.4 \\
\hline Reconstruction interval & 3 & 1 & 5 & 3 & 0.5 & 5 \\
\hline Scan delay (s) & 0 & $4-5$ & 60 & 0 & $7-8$ & 60 \\
\hline $\begin{array}{l}\text { Dose-length product } \\
(\text { DLP) }(m G y \times c m)\end{array}$ & \multicolumn{3}{|c|}{$6-7$} & \multicolumn{3}{|c|}{$5-6$} \\
\hline
\end{tabular}

of $5 \mathrm{~mm}$. Ultimately, in renal transplant donors, 7-10 min delayed scans are obtained for the evaluation of the ureters.

\section{Postprocessing techniques}

Axial source images remain the basis for diagnosis; however, postprocessed 2D and 3D reformations contribute significantly for accurate evaluation. Most commonly used post-processing techniques are multiplanar and curved planar reformations (MPR and CPR), maximum intensity projection (MIP), and volume rendering (VR).

MIP images provide angiographylike images with an excellent overview of vascular anatomy and their variable projection angles should be used for the accurate interpretation of stenotic lesions. MPR and CPR images are particularly useful for correct evaluation of the arterial luminal diameter for accurate depiction and quantification of the arterial stenosis. VR images can be used for the overall display of the abdominal vasculature and can provide an insight for the interpreter and referring physicians $(5,9)$. Finally, the axial source images should always be reviewed for possible presence of an accompanying non-vascular pathology.

\section{Normal renal vascular anatomy}

In the majority of the human subjects, each kidney is supplied by one renal artery arising from the abdominal aorta, but in approximately 30\% of individuals more than one artery can be present (10). Renal arteries are usually 4-6 cm in length and 5-6 $\mathrm{mm}$ in diameter. They typically arise from the aorta at the level of L1-L2 intervertebral disk space below the origin of the superior mesenteric artery (SMA), and tend to course through the anterior portion of the renal pelvis. Both renal arteries usually course in a slightly posterior direction due to the anatomic orientation of the kidneys. The right renal artery orifice is located on the anterolateral wall of the aorta. The left renal artery originates in a more lateral location. The right renal artery characteristically courses downwards toward the right kidney behind the inferior vena cava (IVC), while the left has a more horizontal, upward orientation posterior to the left renal vein (Fig. 3). Each renal artery supplies the inferior adrenal artery. The inferior adrenal arteries arise directly 

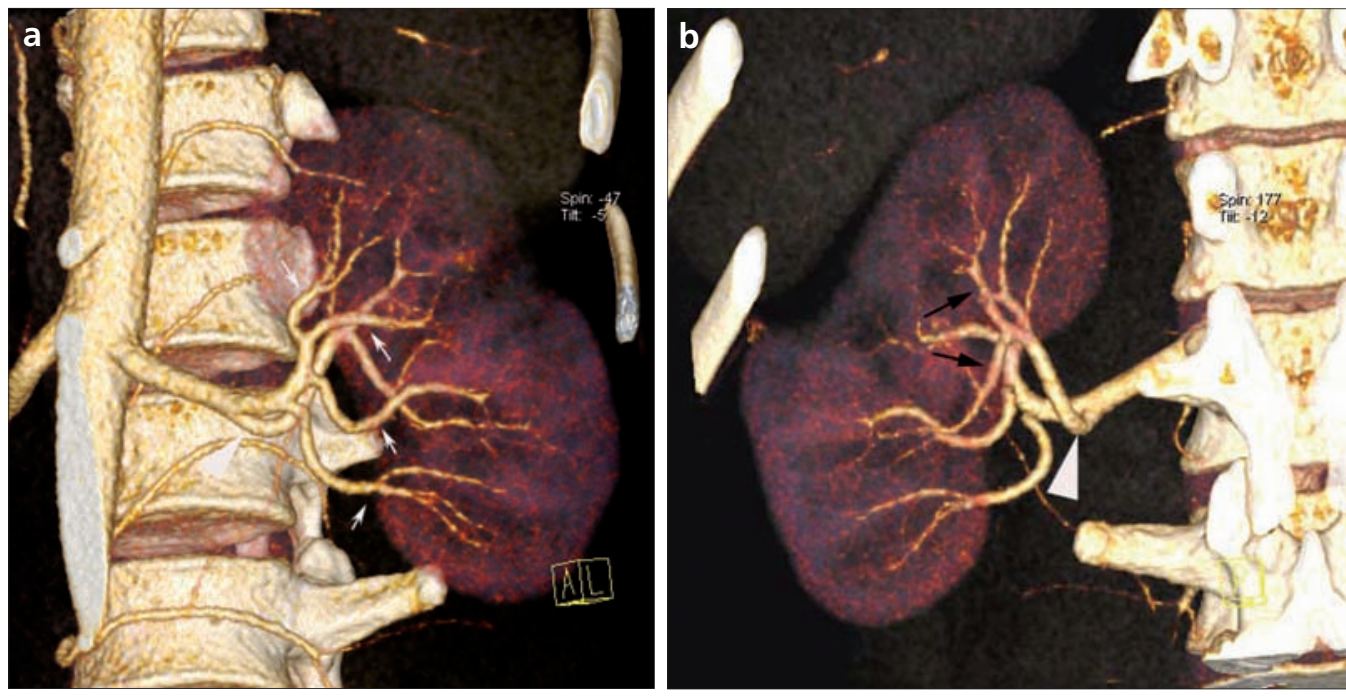

Figure 4. a, b. Coronal volume rendering images show anterior (a) and posterior (b) views of normal segmental anatomy of the renal artery. The first division is the posterior branch (arrowhead). The posterior branch gives two segmental branches (black arrows), supplying the posterior central portion of the kidney. The main renal artery then continues its course before branching into four anterior branches (arrows) at the renal hilum.

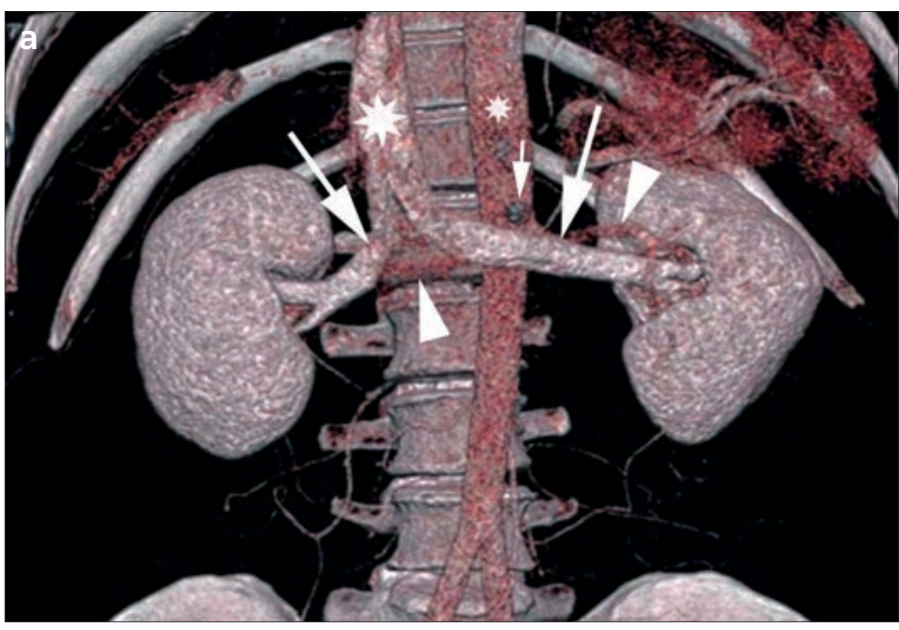

Figure 5. a, b. Coronal (a) and axial (b) volume rendering images show the normal renal vein anatomy. The renal veins (arrows) course anterior to the renal arteries (arrowheads). The left renal vein normally courses between the SMA (thin arrow) and the aorta (small asterisk) before draining into the medial aspect of the IVC (big asterisk), while the right vein drains to the lateral aspect of the IVC.

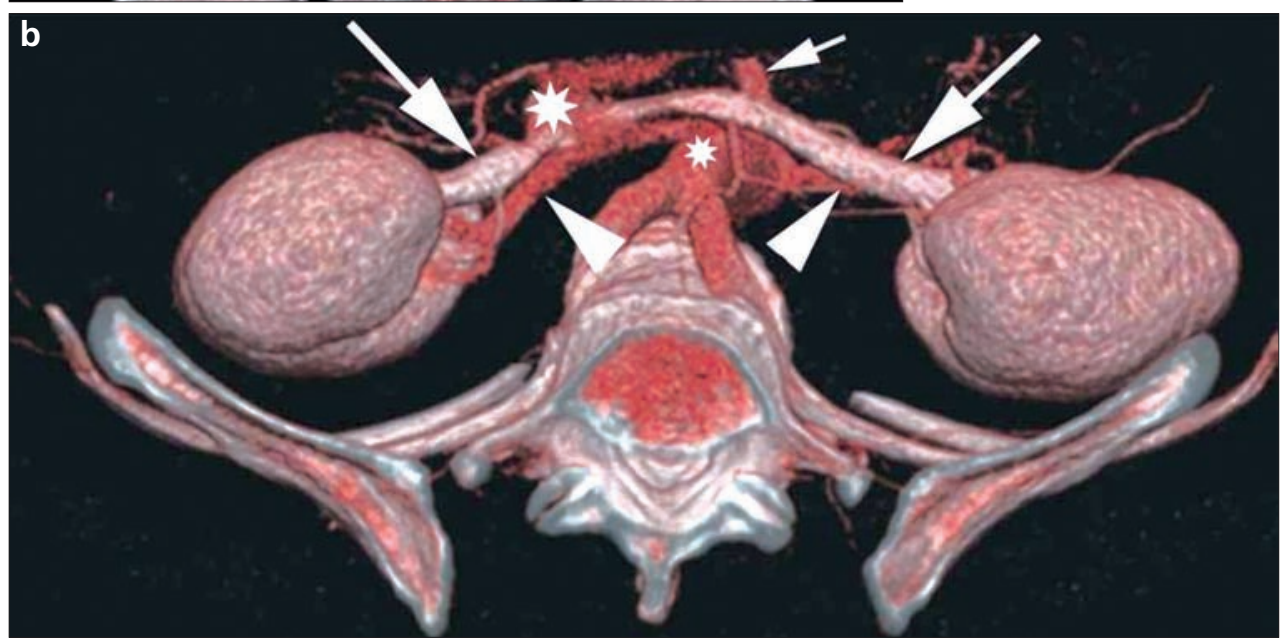

from the proximal renal artery in twothirds of people and they may be solitary or multiple (11). The main renal artery then continues before dividing into four anterior branches at the renal hilum: the apical, upper, middle, and lower anterior segmental arteries (Fig. 4). The segmental arteries then course through the renal sinus and branch into the lobar arteries giving one branch to each pyramid. Further divisions include the interlobar, arcuate, and interlobular arteries.

Renal veins course anterior to the renal arteries. The renal cortex is drained sequentially by the inter- lobular, arcuate, interlobar, and lobar veins, and then they converge to form the main renal vein. The left renal vein normally courses between the SMA and aorta before draining into the medial aspect of the IVC, whereas the right drains into the lateral aspect of the IVC (Fig. 5) (12). 


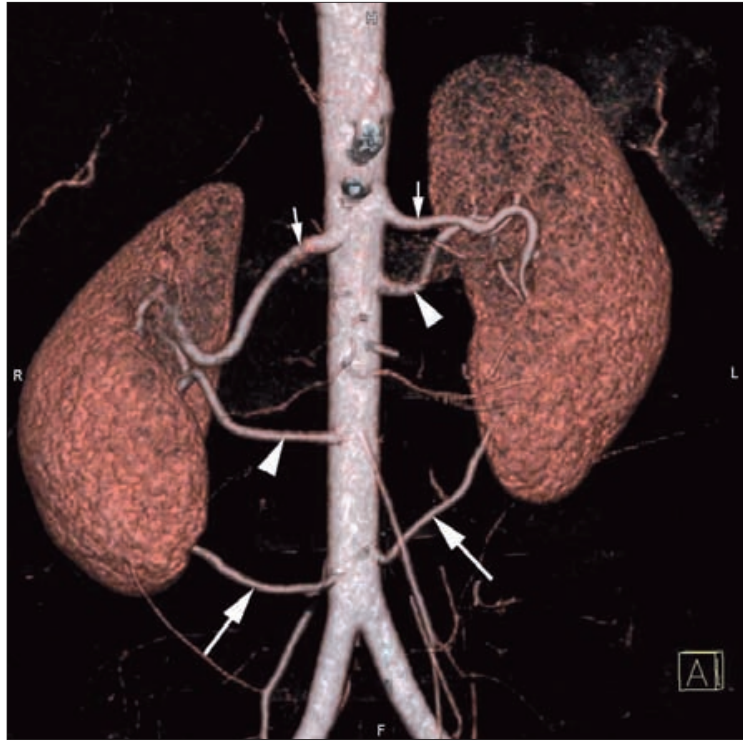

Figure 6. Volume rendering image shows the main renal arteries (thin arrows) and accessory renal arteries. The accessory arteries usually arise from the aorta or iliac arteries, between the levels of T11 and L4. The accessory renal artery (arrowheads) courses into the renal hilum. The polar arteries, a subgroup of accessory renal arteries, enter the renal parenchyma directly from the renal cortex (thick arrows).

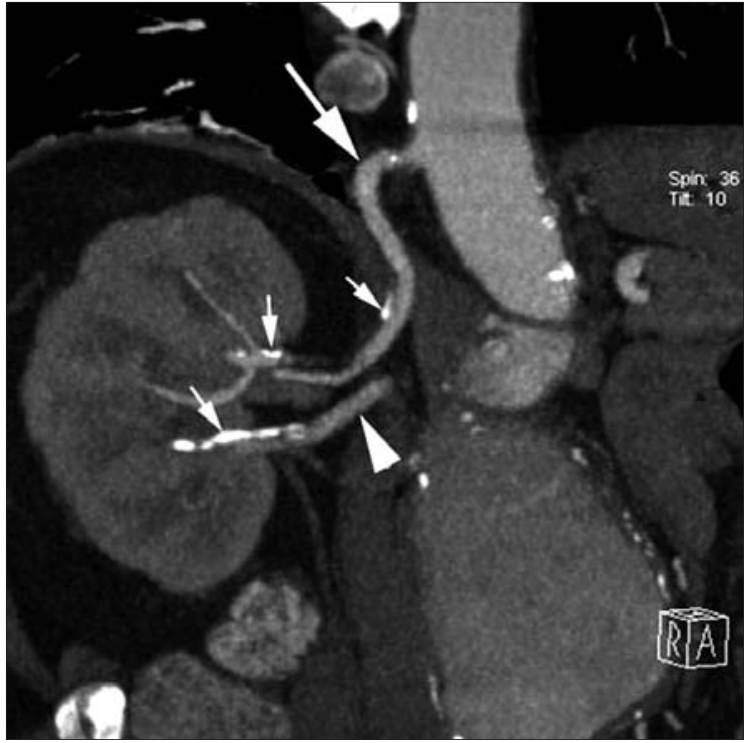

Figure 7. Coronal MPR image shows a rare origin of the accessory renal artery (arrow) which is from the distal part of the thoracic aorta. The main renal artery (arrowhead) emerges at the usual level of the abdominal aorta. Calcific atherosclerotic plaques are seen in the distal parts of both the main and accessory renal arteries (thin arrows).

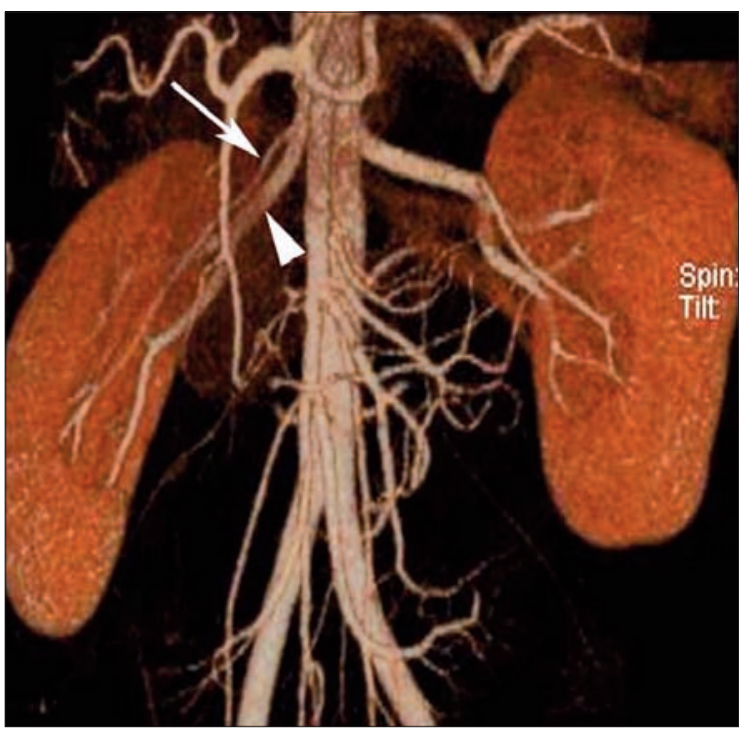

Figure 8. Volume rendering image shows prehilar branching (arrow) of the right renal artery (arrowhead). In this variation, the renal arteries give the segmental renal branches at a more proximal level than the renal hilum. This variant is particularly important for the preoperative mapping of the renal donors.
Sensitivity of CT angiography in demonstration of the course of main renal arteries and veins is around $100 \%$. Accurate depiction of the renal vessels is of paramount importance for potential kidney donors, especially on the left, as it is often the preferred side for renal harvesting (13).

\section{Renal vascular variations Renal artery variations}

Anatomic variations of the renal arteries are common in general popula- tion with different frequencies among several ethnic and racial groups (14). These variations are becoming more important considering the gradual increase in the number of interventional radiological procedures, as well as urological-vascular operations and transplantations (15).

Accessory renal arteries constitute the most common and clinically important renal arterial variations and can be seen in up to one-third of the normal population. Accessory arteries usually arise from the aorta or iliac arteries at any level between T11 and L4. Typically, the accessory renal artery courses into the renal hilum to perfuse the upper or lower renal poles. They may also enter the renal parenchyma directly from the renal cortex, whereupon it may also be termed the polar artery (Fig. 6). Rarely, they may arise from the lower thoracic aorta (Fig. 7), as well as from the lumbar and mesenteric arteries (16). VR, MIP and MPR images may accurately demonstrate accessory arteries. Rubin et al. showed 3D CT angiography to be $100 \%$ sensitive in the visualization of accessory renal arteries $(17,18)$.

Prehilar branching is another common variant that can be readily detected with $3 \mathrm{D}$ imaging. This variant is particularly important for the preoperative mapping of the renal transplant donors. Theoretically, it is the branching of the main renal arteries into segmental branches at a more proximal level than the renal hilum (Fig. 8) (18).

Rarely, renal arteries may originate from the more proximal portion of the abdominal aorta above the origin of the SMA. Aberrant renal arteries may even originate from the iliac arteries in rare cases; however, they can be more common in ectopic kidneys (Fig. 9).

In the case of horse-shoe kidney, the main renal arteries develop normally; 


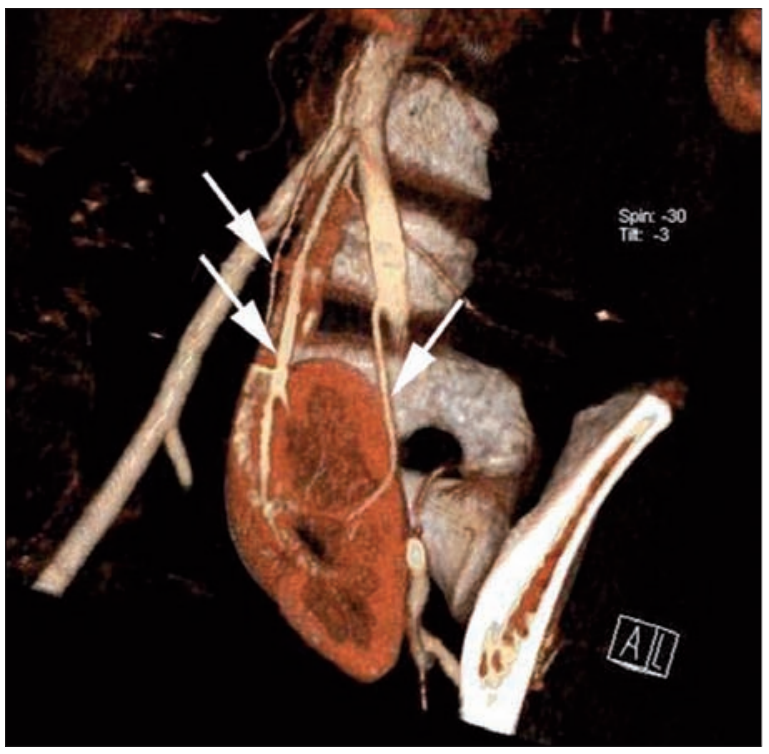

Figure 9. Volume rendering image shows aberrant renal arteries (arrows) of a pelvic kidney. Two of them originate from the left main iliac artery and the third one from the terminal aorta.
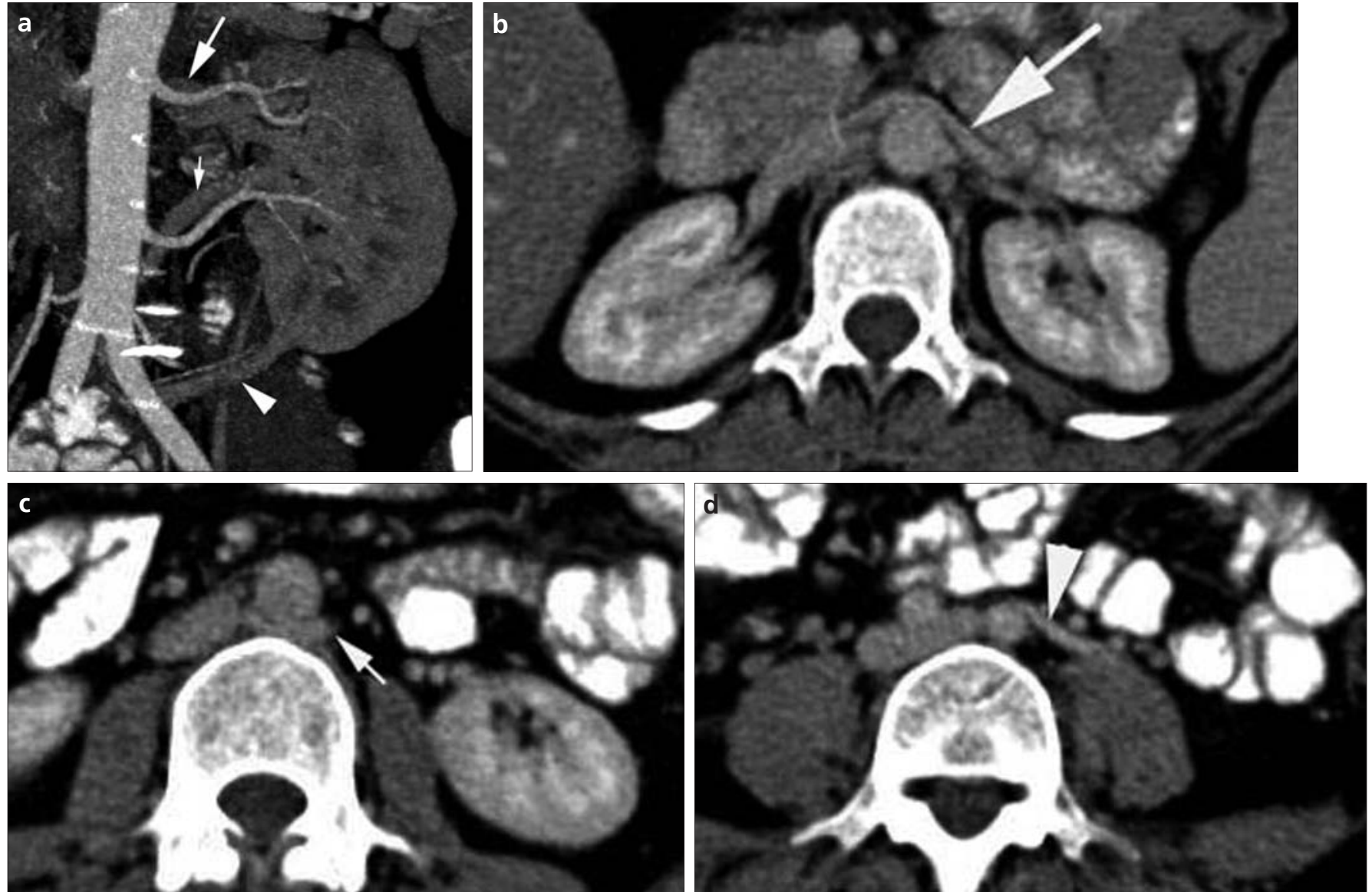

Figure 10. a-d. Coronal oblique multiplanar reconstruction (a) and axial images (b-d) show supernumerary renal veins. There are three renal veins of the left kidney. The superior renal vein (thick arrow) is located at its usual level and drains into the IVC. The middle renal vein (thin arrow) courses between the aorta and vertebral column (retroaortic renal vein) and drains into the terminal part of the IVC. The inferior renal vein (arrowhead) drains into the left iliac vein.

however, the mesenephric and metanephric arteries often persist to supply the upper and lower poles, respectively. These primitive arteries may arise at different levels in the aorta and iliac arteries (19).

\section{Renal vein variations}

The most common venous variant is the presence of supernumerary renal veins which can be seen in approximately $15-30 \%$ of individuals (16), and occasionally the accessory renal vein that can drain into the iliac vein (Fig. 10).

Circumaortic renal vein is another variant in which the left renal vein bifurcates into ventral and dorsal limbs enclosing the abdominal aorta (20). 


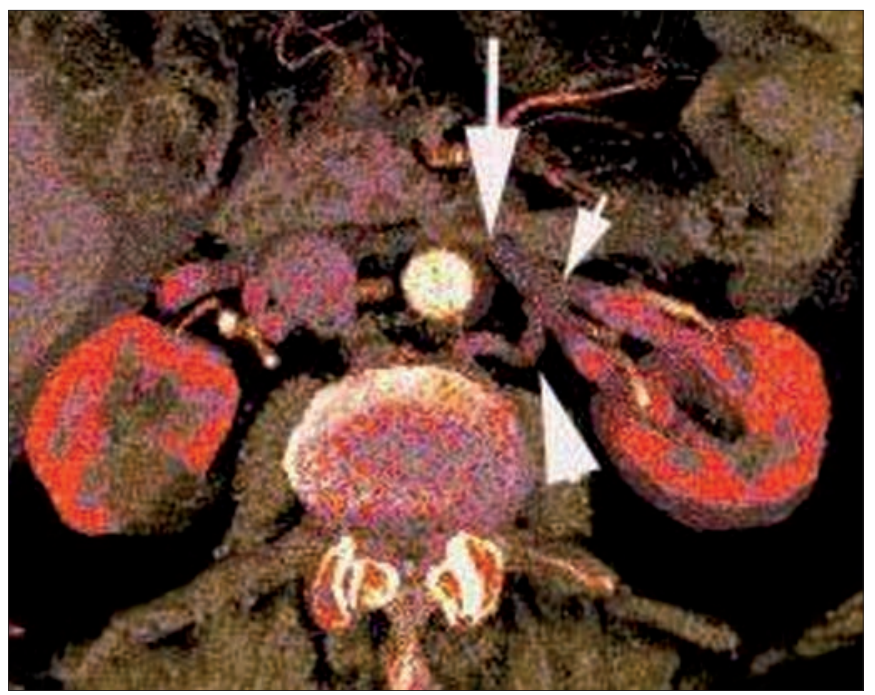

Figure 11. Axial volume rendering image shows a circumaortic renal vein. The left renal vein (thin arrow) bifurcates into ventral (thick arrow) and dorsal (arrowhead) limbs that enclose the abdominal aorta.
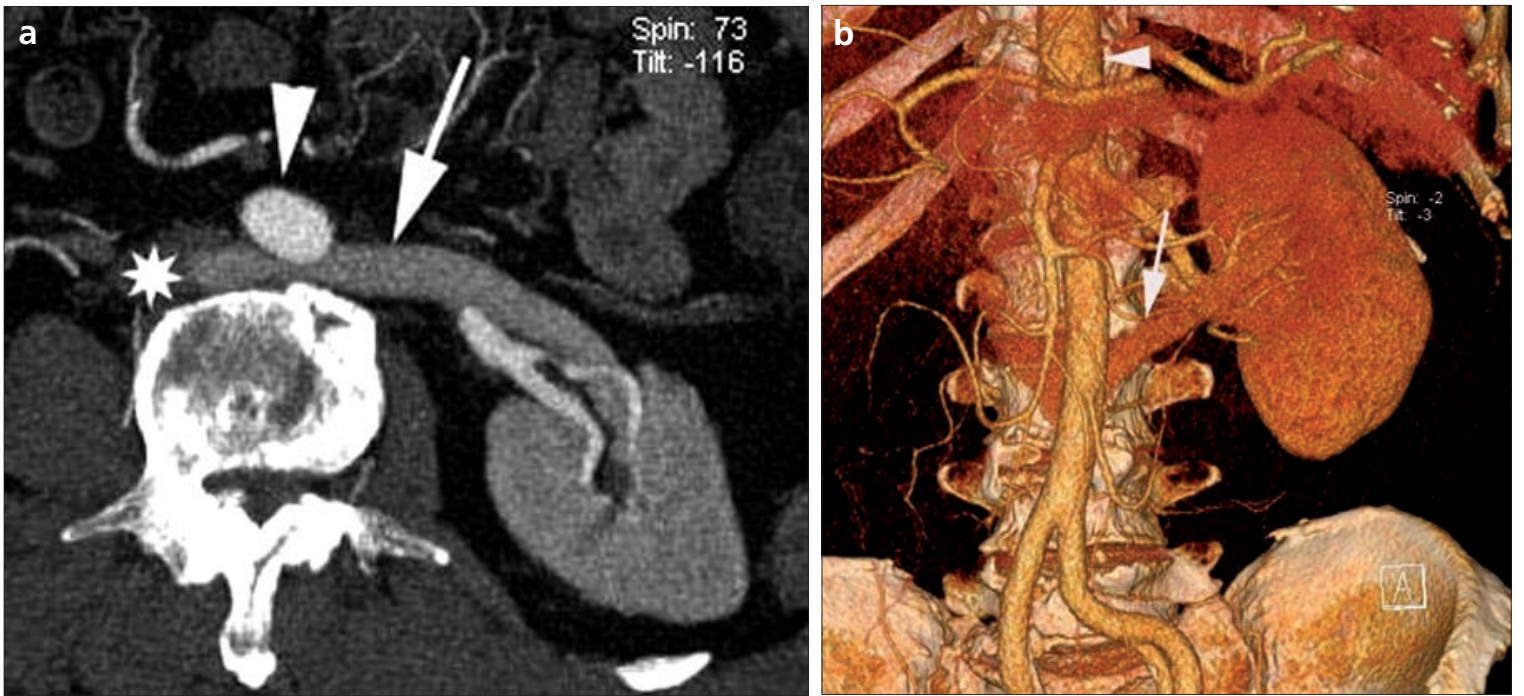

Figure 12. a, b. Axial thin MIP (a), volume rendering (b) images show a retroaortic renal vein. The left renal vein passes (arrow) posterior to the aorta (arrowhead) and drains into the lower part of the IVC (asterisk).

The retroaortic portion is located in a more caudal position with respect to the preaortic one. It has a $2.4-8.7 \%$ prevalence and is particularly important in kidney transplant donors (Fig. 11) (21).

Retroaortic renal vein is a less common venous anomaly which can be detected in $3 \%$ of individuals. In this variant, the left renal vein courses posterior to the aorta and drains into the lower lumbar portion of the inferior vena cava (Fig. 12) (20).

Variations of the renal veins and IVC occur infrequently but if they remain unidentified in potential surgery candidates, that may increase surgical morbidity during operations, therefore it is necessary to evaluate renal veins and azygocaval anatomy correctly (22). Knowing the above- mentioned renal venous variations also carries importance when placement of an inferior vena cava filter is considered.

\section{Conclusion}

Conventional angiography is traditionally regarded as the gold standard imaging modality for evaluation of the renal vasculature. However, MDCTA enables less invasive, accurate, prompt and effective visualization of the renal vessels. MDCTA, together with reformatting techniques, can provide valuable information about not only intraluminal pathologies but also the anatomical variations including the number, size, course, and anatomy of the renal vasculature.

\section{References}

1. Bluemke DA, Cambers TP. Spiral CT angiography: an alternative to conventional angiography. Radiology 1995;195:317319.

2. Prokop M. Multislice CT angiography. Eur J Radiol 2000; 36:86-96.

3. Rubin GD, Shiau MC, Schmidt AJ, et al. Computed tomographic angiography: historical perspective and new state of the art using multi detector row helical computed tomography. J Comput Assist Tomogr 1999; 23:83-90.

4. Toprak U, Erdoğan A, Gülbay M, Karademir MA, Paşaoğlu E, Akar OE. Preoperative evaluation of renal anatomy and renal masses with helical CT, 3D-CT and 3D-CT angiography. Diagn Interv Radiol 2005; 11:35-40.

5. Urban BA, Ratner LE, Fishman EK. Threedimensional volume-rendered CT angiography of the renal arteries and veins: normal anatomy, variants, and clinical applications. Radiographics 2001; 21:373-386. 
6. Türkvatan A, Ozdemir M, Cumhur T, Olçer T. Multidetector CT angiography of renal vasculature: normal anatomy and variants. Eur Radiol 2009; 19:236-244.

7. Ozkan U, Oğuzkurt L, Tercan F, Kizilkiliç $\mathrm{O}$, Koç Z, Koca N.Renal artery origins and variations: angiographic evaluation of 855 consecutive patients. Diagn Interv Radiol 2006;12:183-186.

8. Kawashima A, Sandler CM, Ernst RD, Tamm EP, Goldman SM, Fishman EK. CT evaluation of renovascular disease. Radiographics 2000; 20:1321-1340.

9. Fleischmann D. Multiple detector-row CT angiography of the renal and mesenteric vessels. Eur J Radiol 2003; 45:79-87.

10. Leung DA, Hagspiel KD, Angle JF, et al. MR angiography of the renal arteries. Radiol Clin North Am 2002; 40:847-865.

11. Kawamoto S, Montgomery RA, Lawler LP, Horton KM, Fishman EK. Multi-detector row CT evaluation of living renal donors prior to laparoscopic nephrectomy. Radiographics 2004; 24:453-466.
12. El-Galley RES, Keane TE. Embryology, anatomy, and surgical applications of the kidney and ureter. Surg Clin North Am 2000; 80:381-401.

13. Smith PA, Ratner LE, Lynch FC, Corl FM, Fishman EK. Role of CT angiography in the preoperative evaluation for laparoscopic nephrectomy. Radiographics 1998; 18:589-601.

14. Boijsen E. Renal angiography: techniques and hazards; anatomic and physiologic considerations. In: Baum S, ed. Abrams' angiography. 4th ed. Philadelphia: Little, Brown and Company, 1997; 1101-1131.

15. Khamanarong $\mathrm{K}, \quad$ Prachaney $\mathrm{P}$ Utraravichien A, Tong-Un T, Sripaoraya K. Anatomy of renal arterial supply. Clin Anat 2004; 17:334-336.

16. Kadir S. Angiography of the kidneys. In: Kadir S, ed. Diagnostic angiography. Philadelphia: Saunders, 1986; 445-495.

17. Johnson PT, Halpern EJ, Kuszyk BS, et al. Renal artery stenosis: CT angiographycomparison of real-time volume rendering and maximum intensity projection algorithms. Radiology 1999; 211:337-343.
18. Rubin GD, Alfrey EJ, Dake MD, et al. Assessment of living renal donors with spiral CT. Radiology 1995; 195:457-462.

19. Cocheteux B, Mounier-Vehier C, Gaxotte V, McFadden EP, Francke JP, Beregi JP. Rare variations in renal anatomy and blood supply: CT appearances and embryological background. A pictorial essay. Eur Radiol 2001; 11:779-786.

20. Kahn PC. Selective venography of the branches In: Ferris EJ, Hipona FA, Kahn PC, et al. eds. Venography of the inferior vena cava and its branches. Huntington: Krieger, 1973; 154-224.

21. Minniti S, Visentini S, Procacci C. Congenital anomalies of the venae cavae: embryological origin, imaging features and report of three new variants. Eur Radiol 2002; 12:2040-2055.

22. Mathews R, Smith PA, Fishman EK, Marshall FF. Anomalies of the inferior vena cava and renal veins: embryologic and surgical considerations. Urology 1999; 53:873-880. 